\title{
EU TE DEDICO: HISTÓRIA, EDUCAÇÃO E SENSIBILIDADES NAS DEDICATÓRIAS DE LIVROS DE UM PROFESSOR CATARINENSE (1940- 1980)
}

\author{
Maria Teresa Santos Cunha ${ }^{1}$
}

\section{RESUMO}

O artigo objetiva inventariar e analisar dedicatórias que se encontram em livros pertencentes ao professor catarinense Victor Márcio Konder (1920-2005) cuja biblioteca pessoal encontra-se preservada no Instituto de Investigação e Documentação em Ciências Humanas (IDCH) ligado à UDESC/SC/Brasil. A análise destaca as dedicatórias como indicativas de circuitos de sociabilidades e como modo de identificar circulação, posse e consumo de livros. As dedicatórias são tratadas como atos de linguagem que extrapolam a função comunicativa e conectam-se às intenções dos sujeitos de atribuir autoridade ao que escrevem, produzir sensibilidades em seus interlocutores e, assim, criar fronteiras simbólicas de integração pessoal e afetiva. O estudo dialoga com as bibliotecas pessoais como patrimônios históricos-educativos e registram-se imagens fotográficas de modo a amparar visivelmente o trabalho desenvolvido.

Palavras-chave:Dedicatórias, Bibliotecas Pessoais, História da Educação, Patrimônio Histórico-Educativo.

${ }^{1}$ Universidade do Estado de Santa Catarina (UDESC), Florianópolis/SC, Brasil. 


\title{
TE DEDICO: HISTORIA, EDUCACIÓN Y SENSIBILIDADES EN LAS DEDICATORIAS DE LOS LIBROS DE UN PROFESOR EN SANTA CATARINA (1940-1980)
}

\section{RESUMEN}

El artículo tiene como objetivo inventariar y analizar las dedicatorias que se encuentran en los libros pertenecientes al profesor catarinense Victor Márcio Konder (1920-2005) cuya biblioteca personal se conserva en el Instituto de Investigación y Documentación en Ciencias Humanas (IDCH) vinculados a UDESC/SC/Brasil. El análisis destaca las dedicatorias como indicativos de circuitos de sociabilidades y como una forma de identificar la circulación, posesión y consumo de libros. Las dedicatorias son tratadas como actos de lenguaje que extrapolan la función comunicativa y se conectan a las intenciones de los sujetos de asignar autoridad a lo que escriben, producir sensibilidades a sus interlocutores y así crear límites simbólicos de integración personal y afectiva. El estudio dialoga con bibliotecas personales como patrimonio histórico-educativo e imágenes fotográficas se registran de tal manera que el trabajo desarrollado es visiblemente apoyado.

Palabrasclave: Dedicatorias, Bibliotecas Personales, Historia de la Educación, Património Historico-Educativo.

\section{DEDICATE YOU: HISTORY, EDUCATION AND SENSITIVITIES IN THE DEDICATIONSOF BOOKS OF A PROFESSOR IN SANTA CATARINA (1940-1980)}

\author{
ABSTRACT \\ patrimony.

\section{JE TE DÉDI: HISTOIRE, EDUCATION ET SENSIBILITÉS DANS LES DÉDICACES DES LIVRES D'UNPROFESSEUR À SANTA CATARINA (1940- 1980)}

The article aims to inventory and analyze dedications that are found in books belonging to professor catarinense Victor Márcio Konder (1920-2005) whose personal library ispreserved in the Institute of Research and Documentation in Science Human (IDCH) linked to UDESC/SC/Brazil. The analysis highlights the dedications as indicative of circuits of sociabilities and as a way to identify circulation, possession and consumption of books. The dedications are treated as acts of language that extrapólate the communicative function and connect to the intentions of the subjects to assign authority to what they write, produce sensitivities in their interlocutors and thus create symbolic boundaries of personal and affective integration. The study dialogues with personal libraries as historical-educational heritage and photographic images are recorded in such a way that the work developed is visibly supported.

Keywords: Dedications, personal libraries, History of Education, historical-educational 


\section{RÉSUMÉ}

L'article vise à l'inventoriat et à l'analyse des dédicaces que l'ontrouve dans les livres du professeur catarinense Victor Márcio Konder (1920-2005) dont la bibliothèque personnelle est conservée à l'Institut de recherche et de documentation des scienses humaines (IDCH) liés à l'UDESC/SC/Brésil. L'analysem et enévidence les dédicaces comme indicatifs de circuits de sociabilité et comme un moyen d'identifier la circulation, la possession et la consommation de livres. Les dédicaces sont traitées comme des actes de langage qui extrapolent la fonction communicative et se connect ent aux intentions des sujets d'attribuer l'autorité à cequ'il sécrivent, produis ent des sensibilités chez leurs interlocuteurs et cré en tain sidesfrontières symboliques de intégration personnelle et affective. L'étude dialogue avec les bibliothèques personnelles en tant que patrimoine historico-éducatif et images photographiques sont en registrées de telle sorte que l'œuvre développée est visiblement soutenue.

Mots-clés:Dédicaces, bibliothèques personnelles, Histoire de l'éducation, Patrimoine historique et éducatif. 


\title{
INTRODUÇÃO: TEMPO PRESENTE, SENSIBILIDADES E PATRIMÔNIO HISTÓRICO- EDUCATIVO
}

\begin{abstract}
(...) a sensibilidade marca profundamente a nossa experiência, e aquilo que ouvimos, vemos, tocamos, cheiramos ou saboreamos é tanto aprendido historicamente, quanto define pela via do nosso aparato sensitivo o que seremos, seguimos por registros - escritos, imagéticos, sonoros - que nos permitam compreender os limites e os alcances possíveis do que vimos chamando de história da educação dos sentidos e das sensibilidades, na particularidade que cada ambiência histórica permite captar. (OLIVEIRA, 2018, p.125)
\end{abstract}

O tempo presente evidencia um cenário em que se experimenta a ampliação e o encontro de estudos de cunho histórico que contemplam abordagens de uma renovada história política das sensibilidades. Este encontro entre o político e as sensibilidades resulta em reflexões férteis que permitem captar possibilidades para o historiador de interpretar, no presente, vestígios de passados e, assim, responder mais rápido "à urgência das experiências, situações, das emoções, dos sofrimentos sabendo colocá-los em números e palavras” (HARTOG, 2017, p.39).

Marcando, indelevelmente, a experiência investigativa no tempo presente, os estudos que envolvem a história das sensibilidades se propõem a discutir ações tanto individuais como coletivas que atravessam a vida cotidiana passíveis de serem estudadas em indícios que contemplam "o desafio de histórias singulares e de trajetórias de vida reconectadas ao presente por meio de reconfigurações sensíveis do passado" (LANGUE,2006, p.32). Não se trata, neste artigo, de propor temas insólitos ou marginais, mas de uma tentativa peculiar de construir história a partir da captura sensível de traços objetivos deixados, sob forma de dedicatórias, em livros que compõem o arquivo pessoal de um educador catarinense.

Na clave de uma história conectada das sensibilidades com a história da educação, considera-se este material empírico como integrante do patrimônio 
histórico-educativo ${ }^{2}$ entendido como um conjunto de artefatos materiais e/ou imateriais resultante e/ou produzido em contextos educacionais formais e/ou não-formais situados temporal e espacialmente. Segundo HARTOG (2017), a noção de Patrimônio é uma "palavra de época" pois cria consensos a tal ponto que considerar "um lugar, um edifício, um objeto como patrimônio muda o olhar que se porta sobre ele; permite e proíbe certos gestos" (p. 46), além de abrir horizontes para uma reapropriação cultural de aspectos, espaços e saberes que buscam "reavivar e transmitir uma memória" (p. 45). Nesse teor, o esforço, aqui empreendido, contempla uma transmissão de memórias através do inventário e a análise de dedicatórias como patrimônios escritos portadores de formas e gestos indicativos de circuitos de sociabilidades e modos de identificar circulação, posse e consumo de livros. As dedicatórias são tratadas como atos de linguagem que extrapolam a função comunicativa e conectam-se às intenções dos sujeitos de atribuir autoridade ao que escrevem, de produzir sensibilidades em seus interlocutores e, assim, criar fronteiras simbólicas de integração pessoal e afetiva.

O estudo se efetiva no arquivo que comporta a biblioteca pessoal do professor catarinense Victor Márcio Konder (1920-2005) e que traz, pelas dedicatórias, "traços de escrituralidade (...) que se distinguem como rastros documentais" (RICOEUR,2007,p.177) que exigiram que se considerasse sua dimensão histórica para a compreensão como um patrimônio históricoeducativo.

No Brasil, as pesquisas sobre patrimônio histórico- educativo vêm se constituindo com temas situados em lugares de fronteira, em que se entrecruzam as áreas de História, Educação e Arquivologia, principalmente, e se conectam ao crescente interesse pela memória e pela prática do arquivamento. Organizados, não raro, em uma lógica memorial e emocional, na maior parte

\footnotetext{
2 A denominação de Patrimônio Histórico Educativo se consolida, no campo da História da Educação, a partir da criação da Rede Ibero-americana do Patrimônio Histórico-Educativo que agrega pesquisadores nacionais e internacionais e mantém a Revista RIDPH- R sob coordenação, no Brasil, da Prof ${ }^{a}$ Dra. Maria Cristina Menezes, da UNICAMP/SP.
} 
das vezes a partir de experiências e esforços pessoais, os arquivos pessoais se impõem como espaços de pesquisa imprescindíveis. Sua importância para o historiador se configura como um modo privilegiado de acesso a vestígios de sensibilidades, de encenação de atos rituais, de reconhecimento de diferentes práticas de sociabilidades. (CUNHA, 2015, p.294). O arquivo pessoal do Prof. Victor Márcio Konder, preservado no Instituto de Investigação e Documentação em Ciências Humanas (IDCH), em Florianópolis (SC), abriga o material empírico que corporifica este artigo através do estudo de sua biblioteca pessoal. 3

\section{SOB A RUBRICA DO GUARDADOR DILETANTE}

O livro foi salvo pela biblioteca. A biblioteca é o contrário do livro único. Nem réplica calcada em uma ortodoxia ciumenta, nem acumulação doentia, mas coleção refletida (...) a biblioteca se apresenta a um só tempo como uma continuação do livro e sua metamorfose. (MICHEL MELOT, 2012, p. 108)

Nem bibliófilo, nem colecionador exaustivo: Victor Márcio Konder pode ser reconhecido como um guardador diletante de livros e materiais escolares que manteve informalmente aquilo que, de alguma maneira, fazia sentido para sua trajetória pessoal. Seu arquivo pessoal conserva materiais impressos como livros, cadernos, folders de congressos que, possivelmente, possuíam uma relação mais afetiva que intencional com o colecionador, os quais que podem ser mais significativos e motivadores de interpretação histórica.

Em seu arquivo pessoal encontram-se, além de livros, cadernos de

\footnotetext{
30 Instituto de Documentação e Investigação em Ciências Humanas - IDCH, está vinculado ao Centro de Ciências Humanas e da Educação - FAED, da Universidade do Estado de Santa Catarina - UDESC e aprovado pela Resolução No 030/2012 - CONSUNI/UDESC. Localiza-se à Rua Visconde de Ouro Preto.547/ Florianópolis/SC. Tem como objetivo constituir-se em um espaço de guarda de documentação e memória científica relativas às pesquisas que tenham por objeto a sociedade contemporânea em seus aspectos histórico, educacional e socioambiental. Acesso em: http://www.faed.udesc.br/?id=1033.
} 
aulas (como aluno e como professor) ${ }^{4}$, impressos variados, como recortes de jornais, panfletos e folders de locais que visitava, além de objetos como sua máquina de escrever. Tais guardados parecem confirmar que nunca conseguiremos deixar para trás os vestígios de nossa vida pregressa. Trata-se, enfim, de um arquivo que comporta uma biblioteca pessoal. Os livros foram salvos como portadores de excertos de passados, plenos de vida e de heterogeneidades que foram doados pela família à UDESC, em 2009 e depois salvaguardado no IDCH, em 2013.

Para esquadrinhar a biblioteca de Victor Márcio Konder - e isso vale para qualquer outra intervenção em bibliotecas pessoais - é fundamental realizar aproximações sucessivas ao seu o dono/guardiãoe procurar traçar seu percurso pessoal e de leitor ao longo da vida, pois, a partir disso, as prateleiras repletas de livros poderão produzir sentidos em uma interpretação feita por intermédio do historiador ao evidenciar indícios das ações que envolvem leitura e escrita de seu proprietário nos livros. Este movimento faz parte do ofício do historiador, pois "é ele quem fala e a explicitação de seus critérios e procedimentos é fundamental para definir o alcance de sua fala. Toda operação com documentos, portanto, é de natureza retórica” (MENEZES, 1998, p. 95).

Victor Márcio Konder viveu durante 85 anos. Nasceu em Itajaí (SC) em 03/11/1920 e faleceu em Florianópolis em 2005. Oriundo de uma família de políticos, tanto do lado materno como paterno, cresceu em um cenário político intenso, sendo seu pai presidente do Partido Republicano Catarinense (PRC). No ano de 1930, passou a residir com sua família no Rio de Janeiro. Os motivos para essa mudança estavam relacionados com a chegada de Getúlio Vargas à presidência do país, graças ao movimento de 1930. O medo de represálias políticas fez com que sua família saísse do Estado de Santa Catarina. No Rio de Janeiro, Victor Marcio Konder fez o curso secundário e desde 1935, com apenas 15 anos, iniciou sua militância filiando-se ao Partido Comunista Brasileiro

\footnotetext{
4 Ver: CUNHA, Maria Teresa Santos e SOUZA, Flávia Freitas de. Viver e escrever. Cadernos e escritas ordinárias de um professor catarinense (Século XX). Florianópolis: Editora Insular, 2015 .
} 
(PCB), onde permaneceu até o final dos anos 1950. Como afirma em sua autobiografia (KONDER; RIBEIRO, 2006), Victor Márcio Konder se auto intitulou "revolucionário letrado" por sua atuação política no PCB. O motivo para seu desligamento, no final dos anos 1950, segundo o próprio, seria por razões ideológicas, pois para ele a realidade brasileira tinha suas especificidades e necessitava de uma profunda tolerância o que o PCB não percebia (KONDER, 2002).Em 1972, concluiu o ensino superior em Ciências Sociais (Sociologia) no Instituto de Filosofia e Ciências Sociais na Universidade Federal do Rio de Janeiro (UFRJ) e ainda no Rio de Janeiro trabalhou como jornalista.

Volta a viver em Florianópolis a partir de 1976, a convite de seu primo Jorge Konder Bornhausen, político e governador do Estado a partir de1978. Em 1980, foi concursado e tornou-se professor na então Faculdade de Educação (FAED) da Universidade do Estado de Santa Catarina (UDESC). Ministrou aulas de Antropologia Cultural, Cultura Brasileira, Economia e História da Educação. Victor Márcio Konder, além de professor, também trabalhou como jornalista em Santa Catarina, e exerceu cargos administrativos em órgão públicos, como a direção da Escola de Governo. Órgão criado pela Assembleia Legislativa de Santa Catarina, na década de 1980.

Victor foi possuidor de muitos livros, de diferentes temáticas, de revistas acadêmicas, impressos variados, além de guardar quarenta e cinco (45) cadernos escolares entre 1941 a 1987. Após falecer em 2005, seu acervo, com mais de mil livros, ficou aos cuidados de seus familiares e doado, em 2009. Até 2013, este material ficou preservado na Biblioteca Central da UDESC e, a partir de 2013, estão salvaguardados no IDCH 414 livros, considerados obras raras5, foram higienizados e, juntamente com as revistas, estão guardados em uma sala separada. Sobre estes livros, a tabela I abaixo ilustra o perfil do acervo bibliográfico no IDC.

\footnotetext{
5 Os bibliotecários incluíram os livros de Konder no acervo da própria Biblioteca da UDESC e apenas os livros considerados Obras Raras foram selecionados -pelos critérios dos responsáveis da Biblioteca Universitária (BU/UDESC) - para integrar a coleção que se encontra depositada no IDCH e sobre a qual este texto se refere.
} 
Tabela I - Perfil do acervo bibliográfico de Victor Márcio Konder:/

\begin{tabular}{l|l}
\multicolumn{1}{c|}{ CATEGORIA } & \multicolumn{1}{c}{ EXEMPLARES } \\
\hline Biografias & 42 \\
\hline Ciências & 2 \\
\hline Dicionários & 8 \\
\hline Economia & 31 \\
\hline Educação & 4 \\
\hline Estudos Marxistas & 26 \\
\hline Filosofia & 7 \\
\hline Geografia & 6 \\
\hline História & 83 \\
\hline Literatura & 23 \\
\hline Livros Didáticos & 6 \\
\hline Livros em outro idioma (françês) & 24 \\
\hline Livros em outro idioma (espanhol) & 32 \\
\hline Livros em outro idioma (inglês) & 2 \\
\hline Variados & 118
\end{tabular}

Fonte: IDCH/Elaboração de Carolina Philippi/ Bolsista IC/UDESC, 2010

A listagem sinaliza um perfil de leitor das áreas humanas, com destaque para a História, a Economia e os Estudos Marxistas, cujos livros impulsionavam, até a década de 1950, sua inclinação para a ação e, ao mesmo tempo, se harmonizavam com suas opções teóricas e políticas, bastante evidenciadas em sua autobiografia (KONDER,2002). Os exemplares em espanhol e em francês eram, em sua maioria, obras de cunho marxista, que circulavam à época, de forma mais restrita e quase clandestinas, entre os militantes das causas consideradas revolucionárias. Os livros e seus conteúdos também são documentos sobre a sensibilidade e a vida e anunciam uma relação de classe e de afinidades de leitura do seu possuidor.

Victor Márcio Konder teve projeção intelectual local/regional e, assim,

${ }^{6}$ Nas categorias que se referem ao idioma do livro, agrupam-se exemplares que tratam de assuntos também elencados, como política, história e sociologia, temas prioritários do autor. 
torna-se viável considerá-lo como um intelectual mediador, ou seja, aquele "cuja presença e importância nas várias sociedades e culturas têm grande relevância, porém nem sempre reconhecimento" (GOMES E HANSEN, 2016,p. 9). As autoras argumentam que o intelectual mediador da cultura é aquele que produz novos sentidos e significados ao fazer ressoar conhecimentos, ideias e saberes que lhe são anteriores e reforçam que esta atitude de mediação feita resulta em "alguma circulação entre os grupos, além de certa permanência no tempo" (idem, p.9) Explicam, também, que é comum que este intelectual seja identificado "nos leitores, contadores de histórias e outros agentes educadores encarregados da socialização de crianças e jovens" (p.9). Victor, como um intelectual mediador, foi jornalista, professor universitário e ocupou cargos em instituições culturais, em associações políticas e obteve um lugar de distinção em uma rede de sociabilidades de intelectuais da cidade e do Estado, como anunciam as dedicatórias em seus livros.O conteúdo de sua biblioteca pessoal, aqui estudada se constituiu como um patrimônio histórico-educativo em que os livros e suas dedicatórias atuam como agentes e testemunhas.

\section{DEDICATÓRIAS: ENTRE RITOS E CELEBRAÇÕES}

A palavra dedicatória designa duas práticas semelhantes que é importante distinguir. Ambas consistem em prestar uma homenagem numa obra a uma pessoa, a um grupo real ou ideal ou a alguma entidade de outro tipo. (GENETTE, 2009, p. 109)

Dedicar é verbo, envolve ação e significa (BUARQUE DE HOLANDA, 1989, p. 527) oferecer ou destinar algo com afeto ou dedicação. Consagrar, votar, devotar, tributar; por ao serviço de, também significa afeição profunda, amor, portanto, ações ligadas ao mundo da sensível presente na formulação imaginária do mundo que seres humanos produzem em todos os tempos.

Eu te dedico, ação efetuada na primeira pessoa e escrita em um livro 
oferecido é uma forma de construir redes interativas de sociabilidades e marcas de pertença. A dedicatória comporta um enunciado autônomo a partir de tal menção ao destinatário, considerado como inspirador capaz de apreciar a mensagem e é, igualmente, uma forma de caracterizar a autoria e refletir sobre distintos espaços do escrito. Os estudos recentes acerca de uma História do livro e da leitura no Brasil sinalizam que este universo oferece ao historiador uma gama de questões a serem estudadas, como mostram as pesquisas de DeNipotti e Pereira (2013) sobre livros e dedicatórias, como abordagens importantes no estudo da leitura, dos livros e da palavra impressa. Tais iniciativas contemplam desde a formação e simbologia das bibliotecas, as relações entre leitura e leitores, o estudo das bibliotecas públicas ou particulares, além dos estudos de cada "acessório" que se relacionam com livros, leitores e leitura, como as capas, as formas de letras, as marginálias, os objetos-relíquia e as dedicatórias.

$\mathrm{O}$ ato de oferecer uma obra impressa em homenagem, fazer uma dedicatória manuscrita, constitui-se em um os mais interessantes acessórios do livro. Abordar esta prática é caminho para inventariar redes de sociabilidade, comportamentos e jogos políticos, além do próprio contexto em que se inserem, pois, o universo dos livros é campo de disputa e espaço de poder. Segundo os estudos de Chartier:

O gesto que inicia estas relações de clientela, ou de patrocínio, é o da dedicatória, um verdadeiro rito. Ela pode ser, tratando-se de um impresso, a oferta de uma cópia manuscrita com bela caligrafia e ricamente ornamentada. Pode ser também a dedicatória de um exemplar do livro impresso mas luxuosamente encadernado e impresso (...). Na cena da dedicatória, a mão do autor transmite o livro à mão que o recebe. (...) o autor oferece um livro contendo o texto que escreveu e, em troca, recebe as manifestações da benevolência traduzida em termos de proteção, emprego ou recompensa (CHARTIER, 1998, p.39-40).

Para a efetivação desse trabalho, buscou-se dialogar no solo de várias linguagens, pois inventariar e analisar dedicatórias é tarefa que não se 
caracteriza como um tema típico de uma disciplina em particular, mas como um espaço de encontro de diversas abordagens, capaz de superar reduções prévias e de possibilitar exercícios de sensibilidades: quem dedicou, o que dedicou, onde e em que data, foram atividades realizadas(CUCUZZA, 2002, p.14). A partir do estudo desse arquivo preservado, tentou-se encontrar as diferentes marcas que foram deixadas em suas páginas expressas pelas dedicatórias feitas. Investigar tais práticas abre espaço para uma construção de conhecimentos acerca de uma história das sensibilidadese da educação, pelas trocas e diálogos que esse professor efetuava,

A biblioteca pessoal de Victor Konder, preservada no IDCH, possui um número de cinquenta e dois (52) livros com dedicatórias. Presenteado por amigos, alunos, parentes, colegas de trabalho, o guardador mantém o livro, como forma de respeito, carinho e lembrança. Ana Chrystina Mignot (2003) comenta o significado das dedicatórias e a relação do leitor e seus escritos com o livro:

As dedicatórias ocupam geralmente as primeiras páginas dos livros, permitindo compreender sua circulação. Se as mensagens deixadas por intelectuais em livros enviados a interlocutores privilegiados permitem identificar redes de sociabilidade que são tecidas no universo das leituras, as palavras escritas em livros ofertados por leitores comuns também revelam muitas histórias de amor pela leitura. (...). Os livros guardam também outras escritas. Além das anotações, grifos, marcadores, trazem papeis que identificam os leitores, como ex-líbris e santinhos com mensagens. (p.32)

Quadro 3 - Exemplos de livros com dedicatórias

\begin{tabular}{|l|l|l|l|}
\hline LIVRO/EDITORA & AUTOR & ANO & CATEGORIA \\
\hline $\begin{array}{l}\text { A Filosofia em Reconstrução. } \\
\text { Companhia Editora Nacional }\end{array}$ & John Dewey & 1958 & Filosofia \\
\hline A inflação brasileira. Tb edições & Ignácio Rangel, & 1963 & Economia \\
\hline $\begin{array}{l}\text { A Palaura - a arte da } \\
\text { conversação e da oratória. } \\
\text { Editora, UFSC. }\end{array}$ & Nereu Corrêa, & 1983 & Letras \\
\hline $\begin{array}{l}\text { A redução sociológica. Escola } \\
\text { Tecnica Nacional }\end{array}$ & Guerreiro Ramos & 1958 & Sociologia \\
\hline Antologia Filosofica.Talleres & Jose Gaos & 1941 & Filosofia \\
\hline
\end{tabular}




\begin{tabular}{|l|l|l|l|}
\hline Tipográficos Modelo & & & \\
\hline $\begin{array}{l}\text { Dualidade básica da economia } \\
\text { brasileira. Escola técnica } \\
\text { nacional }\end{array}$ & Inácio Rangel & 1957 & Economia \\
\hline $\begin{array}{l}\text { España Heroica. Editorial } \\
\text { Americale }\end{array}$ & Vicente Rojo & 1942 & História \\
\hline Facundo. Bibliotheca Militar & Sarmiento & 1938 & História \\
\hline $\begin{array}{l}\text { História Popular da Revolução } \\
\text { Praieira. Editorial Vitória, }\end{array}$ & Fernando Segismundo, & 1949 & História \\
\hline $\begin{array}{l}\text { História Sincera da República. } \\
\text { Livraria São José }\end{array}$ & LeoncioBasbaum, & 1957 & História \\
\hline $\begin{array}{l}\text { Lutas de Familias no Brasil. } \\
\text { Companhia editora Nacional }\end{array}$ & L. A. da Costa Pinto & 1949 & História \\
\hline $\begin{array}{l}\text { O Deus Nu O escritor e o } \\
\text { partido comunista. Editora Saga }\end{array}$ & Howard Fast & 1959 & $\begin{array}{l}\text { Estudos } \\
\text { Marxistas }\end{array}$ \\
\hline $\begin{array}{l}\text { O seguro de Crédito. Max } \\
\text { Limonad, }\end{array}$ & Fábio Konder Comparato & $\mathrm{s} / \mathrm{d}$. & Economia \\
\hline Rêde. Edições Sul Para verificação \\
\hline $\begin{array}{l}\text { Teste A B C-Paurenço Filho } \\
\text { da maturidade necessária a } \\
\text { aprendizagem da leitura e } \\
\text { escrita. Comp. Melhoramentos } \\
\text { de S. Paulo }\end{array}$ & & 1955. & Literatura \\
\hline $\begin{array}{l}\text { Uma garganta e alguns } \\
\text { níquens. Aurora }\end{array}$ & Mauricio Vinhas de Queiroz & 1933 & Educação \\
\hline Versos & Aylton Quintiliano & 1958 & Literatura \\
\hline
\end{tabular}

Fonte: Arquivo Konder/ IDCH/ UDESC/Tabela elaborada por Mariane Martins,2013

A tabela permite algumas considerações a respeito do perfil do próprio guardador. A temática e os autores das obras ofertadas sinalizam, em sua maioria, que os livros a ele dedicados se voltam a assuntos de cunho profissional, especialmente voltada às áreas de sua atuação, qual seja, as Ciências Humanas e Sociais. Nelas, também é perceptível sua vinculação ideológica com as ideias comunistas. Por ter sido filiado ao Partido Comunista Brasileiro até 1956, o fato parece não ter significado seu afastamento por completo daquelas ideias e dos amigos que ali fizera, como evidencia esta dedicatória. Alberto Guerreiro Ramos (1915-1982) ${ }^{7}$ foi um sociólogo e político baiano, adepto das ideias do PCB, que teve atuação na ciência social no Brasil, estudando a questão racial. Suas ideias tiveram ressonância entre intelectuais e pensadores de todo o mundo e na sociologia e na política.

7Disponível em :https://pt.wikipedia.org/wiki/Alberto Guerreiro RamosAcesso em 15 de outubro de 2019 
Figura 1:Dedicatória de Guerreiro Ramos, (Acervo Konder/IDCH).

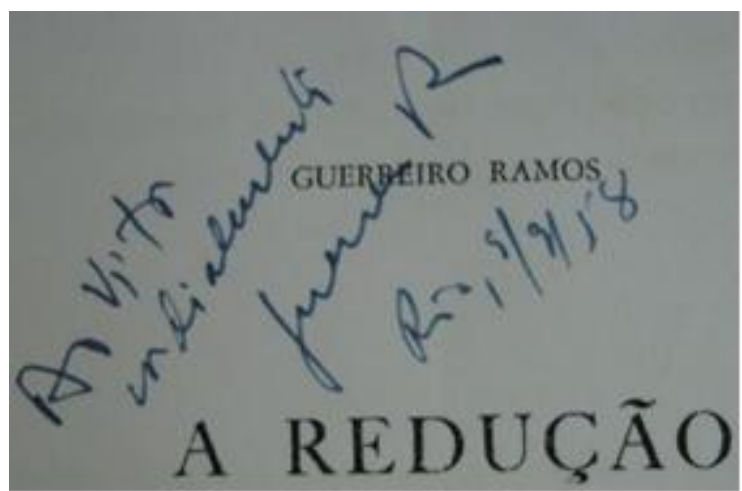

Fonte:RAMOS, Guerreiro. A redução sociológica. Escola Técnica Nacional,1958.

Outro exemplo significativo é a dedicatória feita pelo economista maranhense Inácio Rangel ${ }^{8}$ (1914-1994). Militante do Partido Comunista Brasileiro e cujas ideias sobre desenvolvimento brasileiro foram acolhidas por intelectuais como Celso Furtado, Hélio Jaguaribe e Sérgio Buarque de Holanda.

Figura 2:Dedicatória de Rangel 1958, (Acervo Konder/ IDCH).

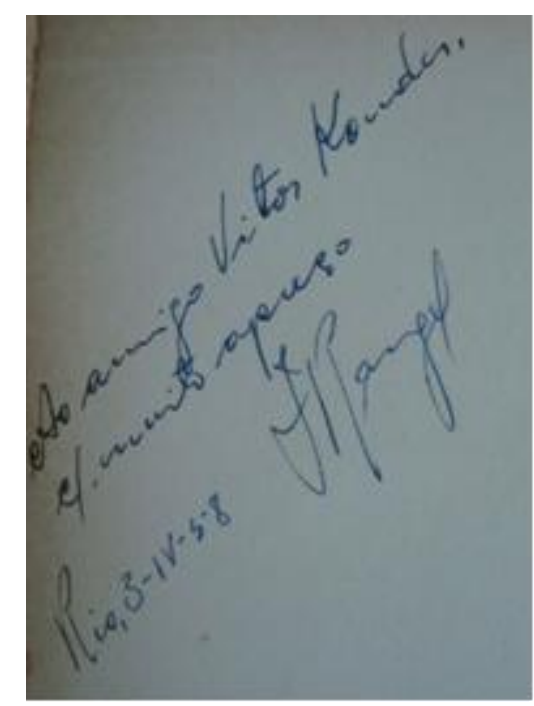

8 Disponível em :https://pt.wikipedia.org/wiki/Ign\%C3\%A1cio Rangel Acesso em 15 de outubro de 2019 
Fonte: RANGEL, Inácio. Dualidade básica da economia brasileira. Escola técnica nacional, 1957.

Um dos mais importantes autores catarinenses também dedicou livro a Victor Márcio Konder: Salim Miguel $^{9}$ (1924-2016) que foi um escritor nascido no Líbano e radicado em Florianópolis(SC) e com ideias vanguardistas. Recebeu o Prêmio Machado de Assis de 2009. Seu arquivo também está preservado no IDCH/UDESC.

Figura 3: Dedicatória de Salim Miguel, (Acervo Konder/IDCH).

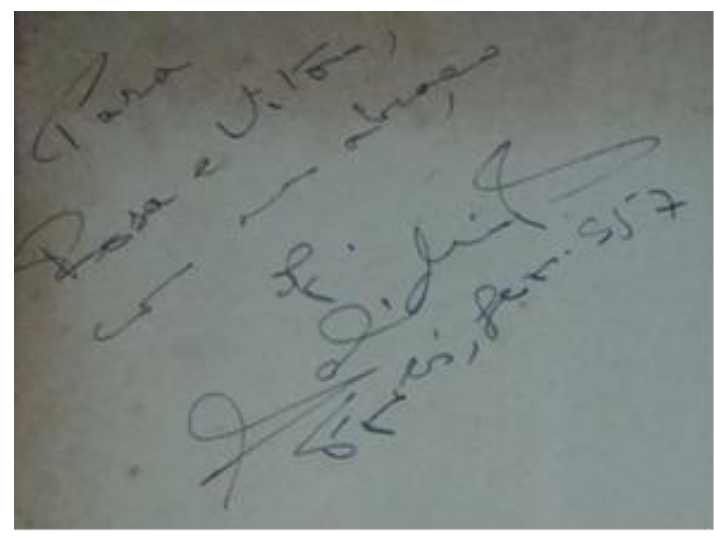

Fonte: MIGUEL, Salim. Rêde. Edições Sul, 1955.

A relação entre a dedicatória e seus atores mostra uma relação entre o autor e outra pessoa, grupo ou entidade. Quem recebe, o dedicatário, é também responsável pela obra que lhe é dedicada e que o autor espera de seu apoio, como leitor. Títulos não estão totalmente ligados ao direto exercício profissional, eles têm variedade exaustiva e pode-se considerar que a diversidade de leituras e ofertas de livros é exercida com um sentido e um olhar qualitativo.

Quadro 2: Dados relacionados as dedicatórias

9 Disponível em:https://pt.wikipedia.org/wiki/Salim MiguelAcesso em 15 de outubro de 2019 


\begin{tabular}{|c|c|c|c|}
\hline DATA & LOCAL & EMISSOR & RECEPTOR \\
\hline $28 / 02 / 1958$ & - & Wilson Ulellos & Victor Márcio Konder \\
\hline $13 / 09 / 1963$ & - & Ignácio Rangel & Victor Márcio Konder \\
\hline $25 / 05 / 1987$ & - & Nereu Corrêa & $\begin{array}{l}\text { Victor Márcio Konder e } \\
\text { Rosa Konder }\end{array}$ \\
\hline $09 / 09 / 1958$ & Rio de Janeiro & Guerreiro Ramos & Victor Márcio Konder \\
\hline $\begin{array}{l}\text { Possivelmente } \\
\text { dezembro }\end{array}$ & - & Alex e Laura & $\begin{array}{ll}\text { Victor Márcio Konder e } \\
\text { Rosa Konder }\end{array}$ \\
\hline 03/04/1958 & Rio de Janeiro & Ignácio Rangel & Victor Márcio Konder \\
\hline- & - & Victor Márcio Konder & Eros \\
\hline- & - & Alex & Victor Márcio Konder \\
\hline- & Rio de Janeiro & Segismundo & $\begin{array}{l}\text { Victor Márcio Konder e } \\
\text { Rosa Konder }\end{array}$ \\
\hline 05/07/1957 & Rio de Janeiro & - & Victor Márcio Konder \\
\hline Abril/1949 & Rio de Janeiro & Costa Pinto & Victor Márcio Konder \\
\hline $17 / 07 / 1955$ & Rio de Janeiro & Osvaldo & $\begin{array}{l}\text { Victor Márcio Konder e } \\
\text { Rosa Konder }\end{array}$ \\
\hline $1^{0} / 10 / 1965$ & São Paulo & $\begin{array}{l}\text { Fábio } \\
\text { Comparato }\end{array}$ & $\begin{array}{l}\text { Victor Márcio Konder e } \\
\text { Rosa Konder }\end{array}$ \\
\hline Fevereiro/1957 & Florianópolis & Salim Miguel & $\begin{array}{l}\text { Victor Márcio Konder e } \\
\text { Rosa Konder }\end{array}$ \\
\hline $13 / 03 / 1984$ & - & - & Victor Márcio Konder \\
\hline 7/09/1947 & - & - & $\begin{array}{l}\text { Victor Márcio Konder e } \\
\text { Rosa Konder }\end{array}$ \\
\hline $30 / 06 / 1958$ & - & Quintiliano & Victor Márcio Konder \\
\hline
\end{tabular}

Fonte: Arquivo KonderIDCH/ UDESC/ Elaboração de Mariane Martins

As dedicatórias, nos livros estudados, eram espaços de celebração. Celebrava-se, por escrito, a amizade, cultuava-se a lembrança, o prazer da partilha, a emoção da dádiva, enfim, pelo exercício de atos sensíveis adentra-se o universo dos livros como espaços de fruição e de poder. Estes sentimentos pareciam mover a escrita das dedicatórias e permitem considerar esta prática como formas simbólicas de poder e marcas de uma cultura, até certo ponto laudatória. As dedicatórias mostravam o afeto do doador em palavras cordiais, na caligrafia desenhada, na cuidadosa ocupação do espaço na página branca: uma ordem que parece dignificar o texto a ser lido e aponta para o aguçamento de sensibilidades.

Espaços de memória. Registro de amizades. Lembranças. O prazer da partilha. Estratégias de consagração. Tessitura de uma rede de relações. Estes sentimentos parecem mover o ato de fazer uma dedicatória em um livro e funcionavam como mediadoras de afeto que circulavam entre amigos ou 
conhecidos. Tal situação, neste acervo, é visível nos livros doados cujas dedicatórias, mostravam uma rede de sociabilidades que se caracterizava pela presença de encontros amistosos entre colegas bem como por uma dada educação das sensibilidades dadas a ver, muito especialmente, pelas práticas da dedicatória livresca.

Segundo estudo de DELMAS (2007), os livros dedicados demonstravam prestígio e a importância do homenageado e são marcas de uma cultura que busca sofisticar suas relações e representações e pode ser considerada uma marca distintiva da sociedade letrada. Aqui a relação é dada pelo tom exortativo, para a leitura exemplar considerada como índice de pensamento e permite pensar em uma leitura autorizada, pela adesão/concordância a uma convicção. O desejo sublinhado pelo doador é um ato mágico e solidário no qual se quer crer seja expressando virtudes de gratidão ou de perdão. Tais práticas, mais uma vez, soam como seguros indícios da passagem do leitor pelo livro, aqui conservada pela memória da escrita de uma dedicatória feita. Esse registro escrito é conhecido e trabalhado pelos historiadores da educação.

\footnotetext{
Associadas a momentos coletivos ou pessoais intensos, à rotina das atividades quotidianas ou a demonstrações de competência escrita, acabam por ser de natureza banal e diversa. Vocacionadas, como única finalidade comum, para deixar marcas, são, além disso, um objeto evanescente, sem contornos definidos. (VIÑAO FRAGO, 2001, p. 44).
}

A dedicatória se enquadra neste tipo de escrita ordinária, anotações que remetem ao uso pessoal, ou seja, escritas que intentam buscar e mostrar fama. As dedicatórias, portanto, são vestígios de práticas sociais porque elas sugerem o que um indivíduo pensava, possivelmente desejava e sua relação com o destinatário (CORADI, 2007). Além disso,

A dedicatória apresenta-se como símbolo das relações políticas, das trocas efetuadas na busca por poder e influência; símbolo de uma política apoiada na hierarquia vigente. O livro e a dedicatória são 
marcas de uma cultura que busca sofisticar suas relações e representações, sendo interessante observar sua utilização por uma elite letrada em meio a uma maioria de iletrados. (DELMAS, 2007, p. 02).

Nota-se que esse material é pleno de história, passível de múltiplas discussões, políticas, sociais, intelectuais. Atualmente, historiadores da educação e das sensibilidades se debruçam nesses objetos, observando grande potencial na análise desses testemunhos escritos. As dedicatórias, como testemunhos escritos, oferecem pistas curiosas a respeito do universo cultural em que estavam inseridos leitores/doadores naqueles tempos.

\section{DEDICATÓRIAS EM OUTRAS (DES)ORDENS POSSÍVEIS}

Se o arquivista se pauta pelo respeito à proveniência do arquivo, à ordem original, o pesquisador, como arquivista anarquista, busca subverter a ordem original, lendo os documentos de outra forma, dentro de outras (des)ordens possíveis. Só assim ele logrará deslocar nossa história cultural, formulando outras maneiras de a ler e interpretar. (MARQUES, 2008, p. 117).

$\mathrm{Na}$ análise de bibliotecas pessoais,convém não negligenciar outros tipos de fontes que podem ser exploradas como problematizações para estudar, por exemplo, a prática de um modo de classificação e mesmo certos hábitos de leitura do proprietário e o microcosmo em que tal biblioteca está incluída. Hospedando-se no tempo como inquilinos de vida, os livros desse arquivo pessoal, com suas marcas de uso e principalmente suas dedicatórias marcam um tempo: as pessoas que se saudaram reconhecem-se como parceiros de uma aventura de amizade, de afinidades eletivas, e de instantes que foram eternizados pela magia da escrita e pela perenidade da leitura. Todas estas inscrições não sãosomente uma "operação abstrata do intelecto; elas são engajamento do corpo, inscrição num espaço, relação consigo e com os outros, 
movidas pelo exercício de amizade" (CHARTIER, 1994, p.17).

São, igualmente, registros de afetos e cultivo de amizades que permanecem como resíduos que, materializados em tinta, papel enfrentam a velocidade e a fugacidade do tempo, eternizam momentos e emergem como exposição de sensibilidades e lembranças de amizades, como registrou a historiadora francesa Anne Vicent-Buffault (1996), para quem:

A amizade é alegria suplementar, local do exercício das sensibilidades, marca de uma eleição, não é uma instituição. Ela estabelece rede de influencias, inventa lugares de convivência e laços de resistência enquanto se multiplicam para a maioria as oportunidades de encontros e interações (..) Nela se conjugam a alegria comum e o ethos... (p. o9)

O levantamento das dedicatórias (obra, autor, ano, local, dedicatário, receptor) datadas em maioria das décadas de 40 e 80, ajudam a confirmar o espaço em que Victor Márcio Konder vivia, assim como sua atuação nesse período, suas redes de sociabilidade que afirmavam suas escolhas pessoais e políticas.Neste mesmo período, é conhecido seu vínculo com o PCB. Os dedicatários, muitos deles autores das próprias obras ofertadas, assumem também esse vínculo com o Partido, uns de maneira mais superficial, como Guerreiro Ramos, outros mais atuantes, como Inácio Rangel. No que tange aos assuntos de cunho comunista, as dedicatórias foram boas fornecedoras de informações. Quando analisados, os autores que dedicaram duas obras a Konder, evidenciou-se, quase em totalidade, uma ligação, sempre presente, com o PCB ou com as ideias provenientes desta proposta.

Assim como Konder, muitos dos dedicatários/autores mostraram-se agentes atuantes no cenário político e/ou cultural brasileiro. O que contribui para pensar que possivelmente havia diálogo entre eles, ou seja, havia uma rede que os unia por interesses em comum. Desta forma, essas dedicatórias ajudam a compor um momento e construir uma memória da vida deste professor, reconhecer pistas de uma dada cultura política de época. Sua biblioteca pessoal 
traz as marcas de um homem militante do comunismo, estudioso desse assunto e que se articulava com aqueles que compartilhavam dessas ideias, o que permite visualizar a formação de um grupo de intelectuais em que Konder participava. Entretanto, a análise da biblioteca mostrou, ainda, títulos ligados ao direto exercício profissional de professor, o que permite considerar uma variedade exaustiva de obras que, certamente, criou condições de leituras em que ,a diversidade foi exercida com um sentido e um olhar qualitativo.

Ao primeiro olhar, não se notam essas informações em uma "simples" dedicatória que apresenta, em geral, palavras afetuosas em letras bem desenhadas. Mas como já é sabido, os documentos não falam sozinhos, precisam da ação do historiador, que os problematiza. Esses registros escritos sob forma de dedicatórias em tantos livros dessa biblioteca pessoal, trouxeram possibilidades de observar o cotidiano vivido por um grupo, com o auxílio do nome dos dedicatários, suas representações e significados das práticas sociais em determinados contextos e, assim, livros, marcas de leitura pela via das dedicatórias se mostram, plenos de histórias possíveis

Ao manter esses livros, Konder também se constituiu como um sujeito leitor graças aos vestígios deixados no interior dos livros. Seus livros, nesta perspectiva, mostram-se como uma tentativa pessoal de se manter vivo e lembrado em cada obra adquirida, anotada e,enfim, guardada e, agora salvaguardada, como um patrimônio histórico-educativo de cunho documental. Estudar, pela via das dedicatórias, comunidades leitoras que registram desejos e homenagens a seus agraciados permite tornar visível um modelo de formação especifica visíveis nas estratégias discursivas utilizadas para dedicar. São exercícios de sensibilidade atravessados pelos diálogos com a história da educação que servem como memórias de um tempo, relacionadas ao campo da docência e da política educacional, além de produziram encantamento, aqui entendido como uma forma de atenção exaltada (GREENBLATT, 1998).

As dedicatórias estudadas mostram indicativos de circuitos de relacionamentos que contribuíram para configurar as ações de seu destinatário, 
o Professor Victor Márcio Konder. Coletá-las e analisá-las revelou assuntos e interesses que permitiram inventariar a formação do arquivo pessoal. Para além de nutrir aspirações, satisfazer gestos, suscitar prazer, inaugurar emoções elas exibem exercícios de amizade e ostentam uma relação intelectual ou privada, real ou simbólica e esta exibição está sempre a serviço da obra como argumento de valorização ou tema de comentário. Este trabalho pretendeu realizar um movimento em que se confere vida às dedicatórias que se escondem em bibliotecas pessoais e que levam à percepção do livro como objeto de investigação transdisciplinar em que se cruzam história, educação, sensibilidades e patrimônios que se mostram e se articulam em função da posse de livros.

Escritas variadas, muitas vezes reunidos sem ordem e ornada por pensamentos salpicados - onde aqui se procurou dar um sentido - permitiram pensar em uma pequena história da dedicatória. O exercício empreendido se caracteriza como fonte de pesquisa para além de uma análise de conteúdo,pois criou possibilidades de uma melhor compreensão da potencialidade heurística de tais materiais. São, também, meios privilegiados que permitem vislumbrar certas dinâmicas de produção e repercussão social do repertório cultural e científico em uma determinada sociedade, pois suscitam lembranças, grafam a ordem do nome e da presença como eixos na tentativa de reconfiguração deste passado através de traços. Em uma (des)ordem possível, pelas dedicatórias, o universo do registro escrito deixado em livros de um professor, se impõem como uma forma de patrimônio e permitem captar sua presença intensa feita de sedução, sensibilidades, recomendação, lisonja, homenagem.Para o historiador, oferecem pistas curiosas a respeito do universo cultural em que estavam inseridos leitores/doadores naqueles tempos. Tantas e tão diferentes marcas permitem imaginar o leitor/doador pela dedicatória, atentar para as palavras sempre cordiais da oferta, reparar na cuidadosa organização gráfica com que se dispunha, na página em branco, a caligrafia nítida, por exemplo. Esta ordem parece antecipar o texto, anunciar um temperamento sensível não só no recurso infinito das palavras como pela visibilidade imperiosa das letras 
desenhadas.

\section{REFERÊNCIAS}

BUARQUE DE HOLANDA, Aurélio. Dicionário Novo Dicionário Aurélio

Da Língua Portuguesa. São Paulo:15ª edição. Nova Fronteira,1989.

BUFFAULT, Anne-Vincent. Da amizade. Uma história do exercício da amizade nos séculos XVIII e XIX.Rio de Janeiro: Jorge Zahar Editores, 1996.

CHARTIER, Roger. A aventura do livro: do leitor ao navegador. SP:Editora da UNESP. 1998.

CHARTIER, Roger. A ordem dos livros. Leitores, autores e bibliotecas na Europa entre os séculos XIV e XVIII. Brasília: Editora da UnB, 1994.

CUCUZZA, Rubem e PINEAU,Pablo (org.). Para una historia de la enseñanza de la lectura y escritura en Argentina. Del catecismo colonial a La Razón de Mi Vida. Buenos Aires: Mino y Dávila Editores. 2002.

CUNHA, Maria Teresa Santos e PHILIPPI, Carolina Cechella. Uma biblioteca sem ordem. Figurações em torno do acervo de livros de um intelectual do século XX. In:Cultura e política: Os usos do passado na escrita da História. Francisco Régis Lopes Ramos e Antonio Luiz Machado (org.). Fortaleza, Núcleo de Documentação Cultural, UFC/ Instituto Frei Tito de Alencar, 2011, p.302315 .

CUNHA, Maria Teresa Santos. Acervos escolares: olhares ao passado no tempo presente. História da Educação. ASPHE - UFPel. v. 19, n.47 p. 293-297, 2015. Disponível em http://www.scielo.br/scielo.php?script=sci arttext\&pid=S22364592015000300293. Acesso: 20 out. 2019.

DELMAS, Ana Carolina Galante. "Do mais fiel e humilde vassalo":as dedicatórias impressas para os monarcas D.João VI e Dona Carlota Joaquina no Brasil. XXIV Simpósio Nacional de História/ ANPUH/ UNISINOS (São Leopoldo/RS), 2007.Disponível em https://anpuh.org.br/uploads/anais-simposios/pdf/201901/1548210412 e8fa8309ff177fe18cdeedb883b36f4f.pdf Acesso em 20 de maio de 2018. 
DeNIPOTI, Claudio e PEREIRA, Magnus Roberto de Mello. Sobre livros e dedicatórias: João e a Casa Literária do Arco do Cego (1799-1801) História Unisinos.17(3):257-271, Set/Dez 2013. Disponível em http://revistas.unisinos.br/index.php/historia/article/viewFile/htu.2013.173.0 6/3720 Acesso em 29 de outubro de 2019

GENETTE, Gérard, Paratextos Editoriais. Cotia,SP: Ateliê Editorial, 2009 ( Coleção Artes do Livro:7).

GOMES, Angela de Castro e HANSEN, Patrícia Santos. (orgs). Intelectuais mediadores: práticas culturais e ação política RJ: Editora Civilização Brasileira, 2016.

GREENBLATT, Stephen. O novo historicismo: Ressonância e encantamento. Estudos Históricos. FGV. Rio de Janeiro, vol4, n.8, 1991, p,244-261.

HARTOG, François. Crer em História. Belo Horizonte: Autêntica, 2017.

KONDER, Rosa Weingold; RIBEIRO, Túlia de Freitas (org.) Victor Márcio Konder: um homem de múltiplas facetas. Florianópolis: Brasília: IEA; ITN, 2006.

KONDER, Victor Márcio. Militância. São Paulo: Arx, 2002.

LANGUE, Frédéric. O sussurro do tempo: Ensaios sobre uma história cruzada das sensibilidades Brasil-França. In: ERTZOQUE, Marina Haizenreder e PARENTE, Temis Gomes (org). História e sensibilidade. Brasília: Paralelo 15,2006. (.p. 21-32.)

MARQUES, Reinaldo. Memória literária arquivada. Aletria, v.18, Belo Horizonte, p.105-119, jul.-dez.2008

MARTINS, Mariane. Bisbliotecando vestígios silenciosos: acervo bibliográfico de Victor Márcio Konder (1920-2005).TCC, UDESC. 2013.

MELOT, Michel. Livro, Cotia, SP:Ateliê Editorial, 2012, (Coleção Artes do Livro)

MENEZES, UlpianoBezerrade. Memória e cultura material: documentos pessoais no espaço público.Estudos Históricos, FGV, v.11, n.21 1998, p.89-103

MIGNOT, Ana ChrystinaVenancio. Papeis guardados.Rio de Janeiro:UERJ, Rede Sirius, 2003.

OLIVEIRA, Marcus Aurélio Taborda, Educação dos sentidos e das sensibilidades: entre a moda acadêmica e a possibilidade de renovação do 
âmbito das pesquisas em história da educação. Revista Brasileira de História da Educação.v.22, ${ }^{0}{ }_{55}$, maio/agosto 2018. p.116-133. Disponível em:https://seer.ufrgs.br/asphe/article/view/76625 Acesso em 15 de outubro de 2019.

RICOEUR, Paul, A história, a memória, o esquecimento. Campinas (SP): Editora da Unicamp, 2007;

VINÃO FRAGO, António. Por uma história da Cultura Escrita: Observações e Reflexões. Caderno do Projecto Museológico, $n^{0} 77$. Santarém. Portugal. 2001.

MARIA TERESA SANTOS CUNHA é Professora Titular do Departamento de História e dos Programas de Pós-Graduação em Historia e Pós-Graduação em Educação da Universidade do Estado de Santa Catarina (UDESC). Bolsista Produtividade em Pesquisa do CNPq-Nível 1-D

E-mail: mariatsc@gmail.com

(b) http://orcid.org/ 0000-0001-6200-6713

Recebido em: 01 de novembro de 2019

Aprovado em: 10 de janeiro de 2020

Revista História da Educação - RHE

Associação Sul-Rio-Grandense de Pesquisadores em História da Educação - Asphe Artigo de acesso aberto distribuído nos termos de licença Creative Commons. 